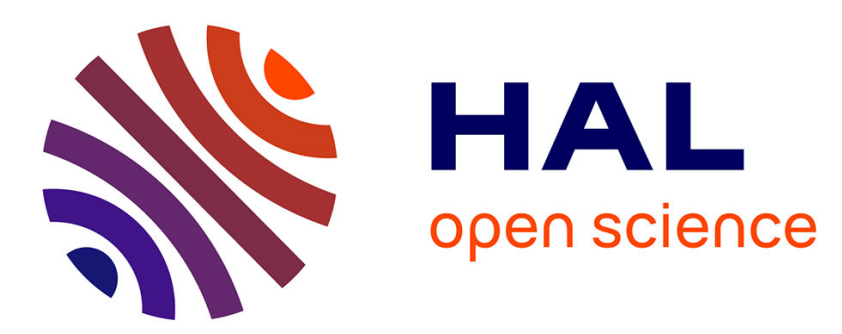

\title{
Effect of Uncertainty about Others' Rationality in Experimental Asset Markets: An Experimental Analysis
}

Eizo Akiyama, Nobuyuki Hanaki, Ryuichiro Ishikawa

\section{To cite this version:}

Eizo Akiyama, Nobuyuki Hanaki, Ryuichiro Ishikawa. Effect of Uncertainty about Others' Rationality in Experimental Asset Markets: An Experimental Analysis. 2012. halshs-00793613

\section{HAL Id: halshs-00793613 \\ https://shs.hal.science/halshs-00793613}

Preprint submitted on 22 Feb 2013

HAL is a multi-disciplinary open access archive for the deposit and dissemination of scientific research documents, whether they are published or not. The documents may come from teaching and research institutions in France or abroad, or from public or private research centers.
L'archive ouverte pluridisciplinaire HAL, est destinée au dépôt et à la diffusion de documents scientifiques de niveau recherche, publiés ou non, émanant des établissements d'enseignement et de recherche français ou étrangers, des laboratoires publics ou privés. 


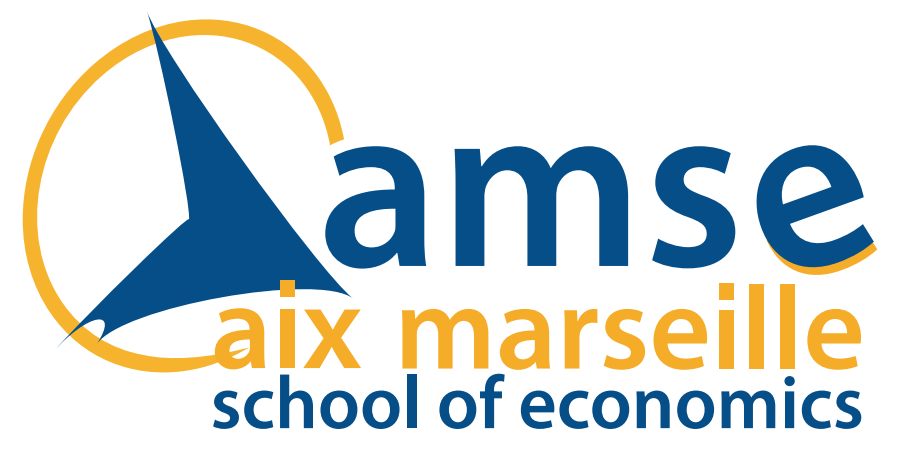

\section{Working Papers / Documents de travail}

Effect of Uncertainty about Others' Rationality in Experimental Asset Markets

An Experimental Analysis

Eizo Akiyama

Nobuyuki Hanaki

Ryuichiro Ishikawa 


\title{
Effect of uncertainty about others' rationality in experimental asset markets: An experimental analysis*
}

\author{
Eizo Akiyama ${ }^{\dagger} \quad$ Nobuyuki Hanaki ${ }^{\ddagger} \quad$ Ryuichiro Ishikawa ${ }^{\S}$
}

November 19, 2012

\begin{abstract}
We investigate the extent to which price deviations from fundamental values in an experimental asset market are due to the uncertainty of subjects regarding others' rationality. We do so by comparing the price forecasts submitted by subjects in two market environments: (a) all six traders are human subjects $(6 \mathrm{H})$, and (b) one human subject interacts with five profitmaximizing computer traders who assume all the traders are also maximizing profit (1H5C). The subjects are told explicitly about the behavioral assumption of the computer traders (in both $6 \mathrm{H}$ and $1 \mathrm{H} 5 \mathrm{C}$ ) as well as which environment they are in. Results from our experiments show that there is no significant difference between the distributions of the initial deviations of the forecast prices from the fundamental values in the two markets. However, as subjects learn by observing the realized prices, the magnitude of deviations becomes significantly smaller in $1 \mathrm{H} 5 \mathrm{C}$ than in $6 \mathrm{H}$ markets. We also conduct additional experiments where subjects who have experienced the $1 \mathrm{H} 5 \mathrm{C}$ market interact with five inexperienced subjects. The price forecasts initially submitted by the experienced subjects follow the fundamental value despite the fact that the subjects are explicitly told that the five other traders in the market are inexperienced subjects. These findings do not support the hypothesis that uncertainty about others' rationality plays a major role in causing substantial deviation of forecast prices from the fundamental values in these asset market experiments.
\end{abstract}

Keywords: Rationality, Common knowledge, Experiment, Asset Markets, Computer Traders

JEL Code: C90, D84

\footnotetext{
${ }^{*}$ We thank Te Bao, Bruno Decreuse, Dimitris Dubois, Cars Hommes, Alan Kirman, Thomas Lux, Julie Rosaz, and Marc Willinger for their comments and suggestions, and Hirofumi Kimiatsuku, Michiko Ogaku, Makoto Soga, and Hiroto Yonenoh for their help in organizing experiments. This project is partly financed by a JSPS-CNRS bilateral research grant, a JSPS-ANR bilateral research grant "BECOA," and financial aids from Japan Center for Economic Research and Japan Securities Scholarship Foundation.

${ }^{\dagger}$ Faculty of Engineering, Information and Systems. University of Tsukuba. E-mail: eizo@sk.tsukuba.ac.jp

¥Aix-Marseille University (Aix-Marseille School of Economics), CNRS \& EHESS, and IUF. Corresponding author. GREQAM 2 Rue de la Charité. 13002 Marseille, FRANCE. E-mail: nobuyuki.HANAKI@univ-amu.fr

$\S$ Faculty of Engineering, Information and Systems. University of Tsukuba. E-mail: ishikawa@sk.tsukuba.ac.jp
} 


\section{Introduction}

Consider an asset with a finite life of $T$ periods. Each unit of the asset pays a constant dividend $D$ at the end of each period, and becomes worthless after the final dividend payment at the end of period $T$. Under these conditions, the fundamental value of a unit of the asset during period $t(t=1,2, \ldots, T), F V_{t}$, is the sum of the remaining dividend payments, i.e., $F V_{t}=(T+1-t) D$. When these conditions are commonly known, the common knowledge of rationality (thus, backward induction) implies that rational traders will trade this asset, if at all, only at its fundamental value.

Following the seminal study by Smith, Suchanek, and Williams (1988), it has been repeatedly shown, for a variety of experimental conditions and subject pools, that the market prices of assets deviate substantially from their fundamental values in these experimental asset markets. ${ }^{1}$

Such deviations of observed prices from fundamental values have been considered to result from the lack of common knowledge of rationality. For example, an interpretation put forward by Smith, Suchanek, and Williams (1988, p.1148) is as follows: "What we learn from the particular experiments reported here is that a common dividend, and common knowledge thereof, is insufficient to induce initial common expectations. As we interpret it, this is due to agent uncertainty about the behavior of others." In other words, as noted by Lei, Noussair, and Plott (2001, p.832), "traders are uncertain that future prices will track the fundamental value, because they doubt the rationality of the other

\footnotetext{
${ }^{1}$ In the original experiment in Smith, Suchanek, and Williams (1988), the value of the dividend payment in each period, $d_{t}$, was determined randomly from a known i.i.d. distribution. Thus, the fundamental value of the asset was $F V_{t}=\sum_{p=t}^{T} E\left(d_{t}\right)$ where $E\left(d_{t}\right)$ is the expected dividend payment. Porter and Smith (1995) eliminates the uncertainty about dividend payments to investigate the effect of varying degrees of risk aversion among subjects. They did not find a significant difference in the observed pattern of mispricing from the model with uncertain dividend payments. While most of the studies, including Smith, Suchanek, and Williams (1988), consider continuous double auction markets, van Boening, Williams, and LaMaster (1993) and Haruvy, Lahav, and Noussair (2007) consider call markets. They report that prices deviate substantially from the fundamental values in call markets also. King, Smith, Williams, and van Boening (1993) investigate the effects of short-selling, margin-buying, equal endowment, and circuit breakers. They also conduct experiments with corporate executives and stock market dealers to see the effect of different subject pools. "Bubbles" and "crashes" were observed in most of their experiment, except in those where transaction fees were introduced, or where subjects had experienced the same market conditions twice. Haruvy and Noussair (2006) show that allowing short-selling can cause prices to deviate substantially below the fundamental values. Noussair, Robin, and Ruffieux (2001) report bubbles in markets with a constant fundamental price, i.e., the expected value of the per period dividend is zero, and an asset is converted into a fixed sum of money at the end of the final trading period. Dufwenberg, Lindqvist, and Moore (2005) mix the twice-experienced subjects and inexperienced subjects to investigate whether the presence of inexperienced subjects among experienced subjects induces greater price deviation. They show that presence of two (respectively four) inexperienced subjects in the market with four (resp. two) experienced subjects (who have experienced the same market three times) did not produce larger price deviations than the market with six twice-experienced subjects. Hussam, Porter, and Smith (2008) study whether (twice) experienced subjects, when facing a new market environment with a large variance in dividend payments and higher initial cash holdings, would avoid creating bubbles. The answer was negative, so learning to trade close to the fundamental values in one market condition did not carry over to a different market condition. Deck, Porter, and Smith (2011) consider overlapping generations of traders to study the effect of the arrival of inexperienced traders and the departure of experienced traders. They find that bubbles form when inexperienced traders arrive and bring liquidity to the market, and that crashes occur when experienced traders leave and withdraw liquidity from the market. See Stöckl, Huber, and Kirchler (2010) and references therein for other experiments.
} 
traders." Lei, Noussair, and Plott (2001) elaborate on this further, stating that "(subjects) speculate in the belief that there are opportunities for future capital gains" and such speculations result in observed price deviations from the fundamental values.

To test this "speculative hypothesis," Lei, Noussair, and Plott (2001) perform a set of experiments in which capital gains are not possible. Based on the observed deviations of prices from the fundamental values even in the absence of possibilities of capital gain, Lei, Noussair, and Plott (2001) reject the speculative hypothesis and conclude that it is not the lack of common knowledge of rationality but individual bounded rationality of some subjects that causes bubbles and crashes in these experimental markets. ${ }^{2}$ Lei, Noussair, and Plott (2001, p. 857) note that "the hypothesis that the traders are rational, and that the bubble is due to the fact that this rationality is not common knowledge, cannot be the whole story behind the bubbles." The study, however, is silent about the extent to which individual bounded rationality and uncertainty about others' rationality play a role in generating mispricing in these experiments.

Two recent papers, Huber and Kirchler (2012) and Kirchler, Huber, and Stöckl (2012), suggest that these bubbles are mainly due to subjects not understanding the nature of declining fundamental values of the asset in the experiment. These studies show that the magnitude of mispricing, the deviation of prices from the fundamental values, becomes much smaller if the instruction shows a figure of declining fundamental values to the subjects, rather than a table containing the same information (Huber and Kirchler, 2012), or if the word "stock" (the value of which many subjects assume not to decline constantly) is explained as "stock is a depletable gold mine" (Kirchler, Huber, and Stöckl, 2012). The latter also suggests that mispricing due to such confusion is further fueled, thus resulting in bubbles and crashes, by increasing the cash-asset ratio during the experiment due to dividend payments. While these two papers make strong cases for the argument that reducing individual confusion makes the magnitude of mispricing smaller, they remain silent about the extent to which uncertainty about others' rationality plays a role in these experiments. We note that subjects better understanding the nature of the experiment does not mean that all subjects believe all the other subjects understand it better. Thus the relevance of uncertainty about others' rationality in these experiments still remains an open question. ${ }^{3}$

\footnotetext{
${ }^{2}$ Lei, Noussair, and Plott (2001) also suggest that subjects in these experiments who are trained to engage in trading simply want to trade because there are no other activities available for them during the experiment. Lei, Noussair, and Plott (2001) call this the "active participation hypothesis."

${ }^{3}$ Recent developments in experimental game theory demonstrate heterogeneity in the depth of strategic thinking by subjects (Nagel, 1995; Ho, Camerer, and Weigelt, 1998; Costa-Gomes and Crawford, 2006). The theoretical
} 
In this paper, we address this open question by eliminating uncertainty about the rationality of other traders in the market through introduction of computer traders. We assume that the computer traders (a) maximize their expected profit without making any error under the assumption that all the other traders do the same, and (b) prefer to trade when they are indifferent between trading and not trading. These assumptions regarding computer traders are explained to all the subjects. We consider two types of markets (treatments) consisting of six traders: one human and five computers (1H5C) and six humans $(6 \mathrm{H})$. Our subjects are also told which treatment they are in, so that, in the 1H5C treatment, the unique human trader does not face any uncertainty about the other traders' rationality.

To facilitate the introduction of computer traders, we employ a call market rule similar to those used by van Boening, Williams, and LaMaster (1993) and Haruvy, Lahav, and Noussair (2007) rather than the continuous double auction employed by Smith, Suchanek, and Williams (1988) and in various other studies. ${ }^{4}$ Notice that, in the absence of any explicit transaction fees (which is the case in our experiment), our computer traders will submit all their orders (both buy and sell orders) at the fundamental value in each period. This means that the market prices in $1 \mathrm{H} 5 \mathrm{C}$ will follow the fundamental values very closely. Thus, comparing the realized market prices between the two treatments, $6 \mathrm{H}$ and $1 \mathrm{H} 5 \mathrm{C}$, is not very informative for our purposes. Therefore, we elicit subjects' expectation about future prices as in Haruvy, Lahav, and Noussair (2007). It has been shown that expected future prices deviate quite substantially from the fundamental values in all human markets (Haruvy, Lahav, and Noussair, 2007, Fig.3, p.1909), and that the deviations disappear gradually as subjects gain more experience from trading under the same market conditions. This is similar to what is observed from the realized prices. Thus, our focus on the forecast prices is informative for studying the cause of realized price deviation.

We next discuss how our design allows us to identify the effect of uncertainty about others'

developments that have followed these experimental findings suggest that considering interaction among heterogeneous boundedly rational agents helps us to better understand experimental outcomes. See Camerer (2003, Ch.5) and Crawford, Costa-Gomes, and Iriberri (2012) for more detail. The way that irrationality or limited rationality at the individual level influences the aggregate outcome depends on the nature of strategic interaction because of how sophisticated subjects act by taking the existence of such boundedly rational agents into account. The importance of the nature of strategic interaction has been pointed out theoretically by Haltiwanger and Waldman (1985) and Haltiwanger and Waldman (1989), and demonstrated experimentally by Fehr and Tyran (2008) in price setting games, by Sutan and Willinger (2009) in beauty contest games, and by Heemeijer, Hommes, Sonnemans, and Tuinstra (2009) and Bao, Hommes, Sonnemans, and Tuinstra (2012) in price forecasting experiments. These experimental results show that in the presence of strategic substitution or negative feedback, the observed outcomes are much closer to the rationally expected equilibrium while in the presence of strategic complementarity or positive feedback, the outcomes deviate substantially from this equilibrium.

${ }^{4}$ van Boening, Williams, and LaMaster (1993) and Haruvy, Lahav, and Noussair (2007) report that prices deviate substantially from fundamental values in call markets as well. 
rationality in the market. Let us imagine a rational human trader. In the $1 \mathrm{H} 5 \mathrm{C}$ treatment, $\mathrm{s} / \mathrm{he}$ does not face any uncertainty regarding the rationality of the other traders in the market. Thus s/he will anticipate the prices to follow the fundamental values. Therefore, if we observe any deviation from this expectation in our data, it must be due to individual bounded rationality (or confusion). On the contrary, in the $6 \mathrm{H}$ treatment, the rational human trader is not sure about the rationality of the other traders in the market and can expect a variety of outcomes including the possibility of capital gains. Of course, we should not eliminate the possibility that subjects are confused or boundedly rational. Thus, the observed deviations of price forecasts from the fundamental values in the $6 \mathrm{H}$ treatment are due to both uncertainty about others' rationality and individual bounded rationality (or confusion). Thus, a comparison of subjects' price expectations in the $1 \mathrm{H} 5 \mathrm{C}$ and $6 \mathrm{H}$ treatments gives us a direct measure of the extent to which uncertainty about the rationality of others explains the deviation of price forecasts from the fundamental values.

Several experiments have introduced computer agents who follow equilibrium behavior in laboratory experiments to reduce uncertainty regarding the rationality of other players. ${ }^{5}$ Cason and Friedman (1997), in their experiments of price formation in a simple market institution, ${ }^{6}$ introduce robot traders who follow a Bayesian-Nash equilibrium strategy to facilitate learning by human subjects. ${ }^{7}$ Fehr and Tyran (2001), which is also discussed in Fehr and Tyran (2005), introduce robots that play the Nash equilibrium strategy in their investigation of nominal (money) illusion to decompose the reason for non-immediate adjustment against negative nominal shocks into (i) those coming from individual irrationality, and (ii) those due to a lack of common knowledge of rationality. Fehr and Tyran (2001) consider price-setting games and vary two aspects of the game: (a) whether or not negative nominal shocks are present, and (b) whether a human subject plays the game with other human subjects or rational computer programs that assume all the players are rational. This two-by-two design allows them to achieve the objective of the experiments. They report that both individual irrationality and lack of common knowledge of rationality equally accounted for the failure

\footnotetext{
${ }^{5}$ Costa-Gomes and Crawford (2006) introduce, in addition to rational robots that follow the equilibrium strategy, boundedly rational robots that follow Level-1,2,3 or Dominance 1,2 strategies in their experiments of a two-person guessing game to better analyze the responses of human subjects who are informed about the behavioral rules of various opponents.

${ }^{6}$ Cason and Friedman (1997) do not consider markets for assets with a life of several periods as we do in this paper.

${ }^{7}$ It should be noted that when human subjects play against other human subjects who are also learning, the learning process can be very slow. In addition to robots that follow the Bayesian-Nash equilibrium strategy (BNE robots), Cason and Friedman (1997) also introduce "Revealing robots" whose behavior is different from BNE robots to investigate whether the convergence to the equilibrium is due to human subjects mimicking the behavior of the BNE robots or due to the best responses against the BNE robots. Their results suggest the latter.
} 
of immediate adjustment to the new equilibrium after a negative nominal shock in the game. ${ }^{8}$

Our experimental results suggest that eliminating uncertainty about the rationality of other traders by introducing profit-maximizing computer traders (who also assume the others behave the same) does not make subjects forecast the prices to follow the fundamental values from the beginning of the experiment. In fact, our experiments show that the deviations of the initial price forecasts from the fundamental values in the $6 \mathrm{H}$ and $1 \mathrm{H} 5 \mathrm{C}$ treatments are not significantly different. After several periods, however, the forecast deviations from the fundamental values become significantly smaller in the $1 \mathrm{H} 5 \mathrm{C}$ treatment than in the $6 \mathrm{H}$ treatment. This dynamic can be understood easily from the fact that realized prices follow the fundamental values in the $1 \mathrm{H} 5 \mathrm{C}$ treatment while, in the $6 \mathrm{H}$ treatment, prices deviate substantially from the fundamental values.

In addition to these two treatments, we consider a treatment with one subject who has experienced the $1 \mathrm{H} 5 \mathrm{C}$ treatment and five other inexperienced subjects who have never participated in similar experiments (1EH5H, where EH $(\mathrm{H})$ indicates experienced (inexperienced) human subjects). The subjects are told explicitly, as in the other cases, the composition of the six traders in their markets. The experienced subjects (EHs) have learned, during their earlier participation in $1 \mathrm{H} 5 \mathrm{C}$ treatment, that the prices follow the fundamental values if they interact with five computer traders, and have adjusted their forecasts accordingly. We hypothesize that, if the uncertainty about others' rationality has a significant effect on how subjects form their expectations about future prices, the initial price forecasts by EHs, who are informed that the other five traders are inexperienced human subjects, should deviate from the fundamental values. Contrary to our expectation, we did not find such initial deviations. Most of the EHs in our experiment initially forecasted prices to follow the fundamental values exactly. After observing that the realized price deviates from the fundamental values, however, our experienced subjects began to expect this deviation.

These results do not support the hypothesis that uncertainty about others' rationality plays a significant role in driving price expectations away from the fundamental values in these asset market experiments. In addition, the way price forecasts evolve for experienced subjects in the $1 \mathrm{EH} 5 \mathrm{H}$ treatment is consistent with the claim that expectations are adaptive and are driven by the patterns of price changes observed by the subjects, as previously reported by Haruvy, Lahav, and Noussair

\footnotetext{
${ }^{8}$ Noussair, Richter, and Tyran (2012) study the effect of nominal shocks in experimental asset markets with constant fundamental values (Noussair, Robin, and Ruffieux, 2001) by changing, in the middle of experiment, the exchange rate between the experimental currency unit and the real currency with which subjects are paid. Noussair, Richter, and Tyran (2012) found that while it took a long time for the price to adjust to the new real fundamental value after a deflationary nominal shock, the same adjustment was immediate after an inflationary nominal shock.
} 
(2007) in a similar experiment (but only with human subjects), and Anufriev and Hommes (2012) and Bao, Hommes, Sonnemans, and Tuinstra (2012) for another class of experiments.

The rest of the paper is organized as follows. The experimental design is discussed in detail in Section 2. Section 3 presents the results of our experiments, and Section 4 concludes the paper.

\section{Experimental design}

We set up an experimental asset market consisting of six traders, who can be either human subjects or computer programs. We consider two treatments. In one treatment, all six traders are human subjects $(6 \mathrm{H}$ treatment). In the other treatment, only one of the six traders is a human subject, and the other five traders are computer traders who try to maximize their profits without making any mistakes while assuming that all the other traders are doing the same (1 $\mathrm{H} 5 \mathrm{C}$ treatment). In each treatment, subjects were told explicitly about the composition of six traders in the market they are participating in, as well as the profit maximizing assumptions of the computer traders. ${ }^{9}$ Our main interest lies in comparing the data between these two treatments to separate the effect of individual bounded rationality or confusion and the uncertainty about others' rationality.

As noted in the introduction, we also conducted an additional set of experiments in which a subject who had participated in the $1 \mathrm{H} 5 \mathrm{C}$ treatment interacts with five inexperienced human subjects $(1 \mathrm{EH} 5 \mathrm{H})$ for a further within-subject investigation. In these experiments, as in the other treatments, the subjects are told about the behavioral assumption of computer traders as well as the exact composition the six traders in their group (that one trader has participated in the $1 \mathrm{H} 5 \mathrm{C}$ treatment while the other five traders have never participated in a similar experiment).

In each market, traders could trade an asset with a life of ten periods. Initially, all traders are endowed with 2 units of asset and 260 units of experimental currency unit (ECU, which was called Mark). Subjects are also asked to submit their expectations regarding the future prices of a unit of the asset. We first describe the trading rule employed, and then proceed to how subjects' expectations about future prices were elicited.

\footnotetext{
${ }^{9}$ That is, we explain the assumptions about computer traders to the subjects who participate in the $6 \mathrm{H}$ treatment as well. The English translation of the exact statement we use to explain the behavior of computer traders is as follows: "Each computer trader assumes that all the traders maximize their profits without making any mistakes. Given this assumption about the others, the computer trader maximizes his profits without making mistakes. If the computer trader is indifferent between trading and not trading, he prefers to trade." In our experiment, this means that computer traders submit orders at fundamental values in each period respecting the budget constraint explained below. We did not tell subjects that computer traders submit their orders at FVs to avoid that trading strategy becoming the focal strategy and being followed by subjects from the beginning.
} 
We use a call market rule that is similar to the one in Haruvy, Lahav, and Noussair (2007). In each period, each trader can submit at most one buy order and one sell order. ${ }^{10}$ An order consists of a pair of a price and a quantity. When submitting a buy order, a trader must specify the maximum price, $P D$, at which $\mathrm{s} /$ he is willing to buy a unit of asset, and the maximum quantity, $Q D$, s/he is willing to buy. In the same manner, when submitting a sell order, a trader must specify the minimum price, $P S$, at which $\mathrm{s} /$ he is willing to sell a unit of asset, and the maximum quantity, $Q S, \mathrm{~s} /$ he is willing to sell. We introduce three constraints: the admissible price range, the budget constraint, and a minimum rationality constraint. The admissible price range is set so that, when $Q D \geq 1(Q S \geq 1), P D(P S)$ must be an integer between 1 and 600 , i.e., $P D \in\{1,2, \ldots, 600\}$ (PS $\in\{1,2, \ldots, 600\})$. The budget constraint here simply means that neither borrowing of cash nor short-selling of an asset is allowed. ${ }^{11}$ The minimum rationality constraint means that, when a trader is submitting both buy and sell orders, i.e., $Q D \geq 1$ and $Q S \geq 1$, the maximum buying price must be no greater than the minimum selling price, i.e., $P S \geq P D$. Once all the traders in the market have submitted their orders, the computer calculates the price that clears the market, ${ }^{12}$ and all transactions take place at that price among traders who submitted a maximum buying price no less than, or a minimum selling price no greater than, the market clearing price. ${ }^{13}$ If no price exists that allows positive transactions, no transaction takes place. We give the market clearing price as zero in the case of no transaction.

At the end of each period, a unit of the asset pays $12 \mathrm{ECU}$ as a dividend. We have chosen a certain dividend payment, instead of a stochastic dividend as commonly considered in the literature, to eliminate the possible effects that varying degrees of risk aversion among traders may have on the experimental outcome. ${ }^{14}$ The dividend can be used to purchase the asset in the following periods. After the final dividend is paid at the end of period 10, the asset has no value. Other than this stream of dividend payments, the asset has no intrinsic value. Thus the fundamental value of a unit of asset at the beginning of period $t$ is $F V_{t}=12 \times(11-t) .{ }^{15}$ We next explain how expectation

\footnotetext{
${ }^{10}$ Of course, a trader is allowed to not submit any orders by specifying the quantities to both buy and sell as zero. There is a 60 second, non-binding, time limit, in submitting orders. When the time limit is reached, the subjects were simply told, though a flashing message in the upper right corner of their screen, to submit their orders as soon as possible.

${ }^{11}$ Thus the budget constraint implies (i) $Q D \times P D \leq$ cash holding at the beginning of the period, and (ii) $Q S \leq$ units of asset on hand at the beginning of the period.

${ }^{12}$ When there are several such prices, the average price which is rounded down to an integer is chosen as the market clearing price

${ }^{13}$ Any ties among the last accepted buy or sell orders are broken randomly.

${ }^{14}$ Porter and Smith (1995) show that eliminating uncertainty about the dividend payments did not significantly lower the magnitude of price deviations from the fundamental values.

${ }^{15}$ We distributed a table showing the sum of the remaining dividends after the dividend for each period was paid
} 
about future prices was elicited.

At the beginning of each period, subjects were asked to submit their price forecasts for all the remaining periods of the market. That is, in period $t$, each subject submitted $10-t+1$ forecasts. ${ }^{16}$ Therefore, subjects are submitting a total of 55 price forecasts over the 10 periods. Each price forecast can be an integer value between 0 and 600 , where 0 represents forecasting no transaction. Subjects were told that they would receive the following bonus payments according to how accurate their forecast prices were:

Bonus (in ECU) $=0.5 \% \times($ Number of forecasts that were within $\pm 10 \%$ of the actual market price $)$ $\times$ Final cash holding in period 10 .

Therefore, if all 55 forecasts were within $10 \%$ of the realized prices, the subject could receive $27.5 \%$ of his/her final cash holding as a bonus payment. ${ }^{17}$ This incentive scheme for accurate forecasts was chosen to reduce subjects' incentive to influencing the prices to move closer to their forecasts by making losses. ${ }^{18}$ When submitting price forecasts, all previous market clearing prices are shown on the screen. Our design is closely related to that used by Haruvy, Lahav, and Noussair (2007), who showed substantial deviation of both realized price and price forecasts from the fundamental values. ${ }^{19}$

The call market rule has several advantages: (i) the prices subjects have to forecast are clear, (2) learning based on observing orders submitted by other traders within a period is not possible, (3) it is easier to introduce computer traders because all orders are submitted simultaneously, and

out, the value we called "next value" in the experiment. Thus subjects had a table showing $F V_{t}$ for $t=2, \ldots, 10$. We also conducted sessions where subjects were given a figure showing the next values in addition to the table. In the session with the figure showing the declining next value, we conducted a control quiz to test the understanding of the subjects at the end of the instruction. Our measure of the deviations of forecasted prices from the fundamental values were not statistically different, unlike the magnitude of price deviations reported by Huber and Kirchler (2012), between sessions with and without the figure showing the declining fundamental value. See the appendix for details.

${ }^{16}$ There was a 120 second, non-binding, time limit for submitting price forecasts. When the time limit was reached, the subjects were simply told, through a message flashing in the upper right corner of their screen, to submit their forecasts as soon as possible.

${ }^{17}$ Therefore, if a subject forecasts that there will be no transaction, there must indeed be no transaction for the subject to receive the $0.5 \%$ bonus.

${ }^{18}$ As noted by Haruvy, Lahav, and Noussair (2007), there is a trade-off between an incentive for accurate transactions and an incentive for maximizing profit from trading. That is, because we ask subjects to submit their forecasts before submitting their order, it is possible that when the incentive for accurate forecasts is too strong, subjects submit potentially loss-making orders to influence the prices to be closer to their forecasts. In our design, since the bonus for accurate forecasts is a fraction of the final cash holding, this incentive will be reduced. It is, of course, best to have both accurate forecasts and high profit from trading.

${ }^{19}$ Huber and Kirchler (2012) report that asking subjects about what the fundamental value of the asset will be in the next period can significantly reduce deviations of the realized price from the fundamental value in an experimental asset market under continuous double auction. 
(4) because all subjects submit their order once in each period, the possible effect of the "active participation hypothesis" (Lei, Noussair, and Plott, 2001) is reduced. ${ }^{20}$

As the end of each period, subjects are informed about the market clearing price for the period, the units of asset they have traded, ${ }^{21}$ their cash and asset holdings, the (total) number of price forecasts that were within $10 \%$ of actual market prices up to that period, and the next value of a unit of the asset. ${ }^{22}$

As noted above, each trader is given an endowment of $260 \mathrm{ECU}$ of cash and two units of the asset before the market opens in period 1 . The same group of traders, with identical initial endowment of cash and the asset, repeat the same 10-period market three times in one experiment. We call a 10-period market a round. Thus, the experiment consists of 3 rounds of a 10-period market with identical initial endowments and the same group of subjects. The purpose of repeating the round three time is to compare how quickly the price forecasts and the market clearing prices converge to the fundamental values. ${ }^{23}$

At the end of the experiment (after participating in 3 rounds of a 10-period market), subjects were paid in cash according to the sum of their final cash holdings (including a bonus payment for accurately predicting future market prices) for each round, plus a participation fee of 500 yen. The exchange rate between ECU and Japanese yen was 1 ECU $=2$ Japanese yen. The experiment lasted about two and a half hours including the instruction and a questionnaire after the experiment.

\section{Results}

The set of computerized experiment was conducted at the University of Tsukuba. ${ }^{24} 226$ subjects were recruited from across the campus by e-mails and flyers..$^{25}$ Most of the subjects were undergraduate students, while 11 were graduate students. Fifty-three of the 226 subjects were from the College of Policy and Planning Sciences (CPPS) in which Economics is one of the majors. ${ }^{26}$ Table 1 summarizes

\footnotetext{
${ }^{20}$ According to the active participation hypothesis, subjects may engage in loss-generating trades rather than not trading because they have no other activity during the experiments.

${ }^{21}$ This information was shown so that a positive (resp. negative) number meant that they had bought (resp. sold) a certain number of units of asset.

${ }^{22}$ The next value of an asset at the end of period $t$ is $12 \times(10-t)$.

${ }^{23}$ Before entering round 1 , there was a practice period to allow subjects to familiarize themselves with the user interface of the software. Subjects were given their initial endowment of cash and asset, and asked to enter their price forecasts for 10 periods and their orders for period 1. The information regarding the resulting market clearing price and so on were not shown to the subjects.

${ }^{24}$ The experiments are implemented with z-tree (Fischbacher, 2007).

${ }^{25}$ Of these 226 subjects, 16 participated in the experiment twice, first in $1 \mathrm{H} 5 \mathrm{C}$ and second in $1 \mathrm{EH} 5 \mathrm{H}$ as the $\mathrm{EH}$.

${ }^{26}$ We are not able to identify their major.
} 


\begin{tabular}{cccc} 
Treatment & Number of Subjects & CPPS & Date \\
\hline $1 \mathrm{H} 5 \mathrm{C}$ & 8 & 2 & June $3,2012(\mathrm{AM})$ \\
$6 \mathrm{H}$ & 24 & 16 & June $3,2012(\mathrm{AM})$ \\
$1 \mathrm{EH} 5 \mathrm{H}$ & $48(8$ as EH $)$ & $14(2$ as EH $)$ & June $3,2012(\mathrm{PM})$ \\
$1 \mathrm{H} 5 \mathrm{C}$ & 17 & 3 & July $7,2012(\mathrm{AM})$ \\
$6 \mathrm{H}$ & 24 & 3 & July $7,2012(\mathrm{AM})$ \\
$1 \mathrm{EH} 5 \mathrm{H}$ & $48(8$ as EH $)$ & 6 & July $7,2012(\mathrm{PM})$ \\
$1 \mathrm{H} 5 \mathrm{C}$ & 25 & 5 & Sep. 22, 2012 $(\mathrm{AM}+\mathrm{PM})$ \\
$6 \mathrm{H}$ & 48 & 4 & Sep. 22, 2012 $(\mathrm{AM}+\mathrm{PM})$ \\
\hline \hline
\end{tabular}

Table 1: Summary of experimental sessions. 1EH 5H: subjects who participated in the $1 \mathrm{H} 5 \mathrm{C}$ session in the morning (AM) were recruited to interact with inexperienced subjects in the afternoon (PM) the same day. CPPS indicates the number of subjects from the College of Policy and Planning Sciences.

the experimental sessions.

In this section, we first discuss the price forecasts and their deviation from the fundamental values in the $1 \mathrm{H} 5 \mathrm{C}$ and $6 \mathrm{H}$ treatments. We then move on to discussing the results from the $1 \mathrm{EH} 5 \mathrm{H}$ treatments.

\section{$3.1 \quad 1 \mathrm{H} 5 \mathrm{C}$ vs. $6 \mathrm{H}$}

Figure 1 shows the initial (i.e., from period 1 of round 1) deviation of the forecast prices from the fundamental values for each subject in $1 \mathrm{H} 5 \mathrm{C}$ (left) and $6 \mathrm{H}$ (right). There are 50 subjects in $1 \mathrm{H} 5 \mathrm{C}$ and 96 subjects in $6 \mathrm{H}$. It is obvious from Figure 1 that there are a few subjects, both in $1 \mathrm{H} 5 \mathrm{C}$ and in $6 \mathrm{H}$, whose initial forecast deviations are much larger than those of the others.

In each period, subjects are forecasting prices for all the remaining periods within a round. To better summarize the magnitude of forecast deviations from the fundamental values for each subjects, we construct two measures of deviation by applying the measures of price deviations from the fundamental values, the relative absolute deviation (RAD) and the relative deviation (RD), proposed by Stöckl, Huber, and Kirchler (2010).

For subject $i$, the deviation of forecast prices from the fundamental values in period $t$ and round $r$ are measured by $b R A D_{t, r}^{i}$ and $b R D_{t, r}^{i}$ defined as:

$$
\mathrm{bRAD}_{t, r}^{i}=\frac{1}{N-t+1} \sum_{p=t}^{N} \frac{\left|f_{t, p, r}^{i}-F V_{p}\right|}{|\overline{F V}|}
$$



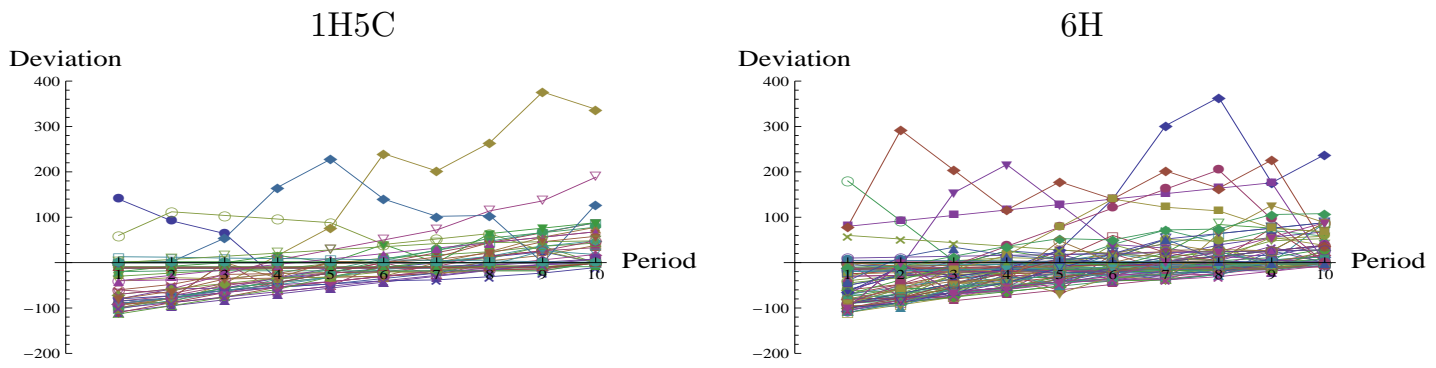

Figure 1: Deviations of price forecasts (in period 1, round 1) from the fundamental values over ten periods for each subject for $1 \mathrm{H} 5 \mathrm{C}$ and $6 \mathrm{H}$.

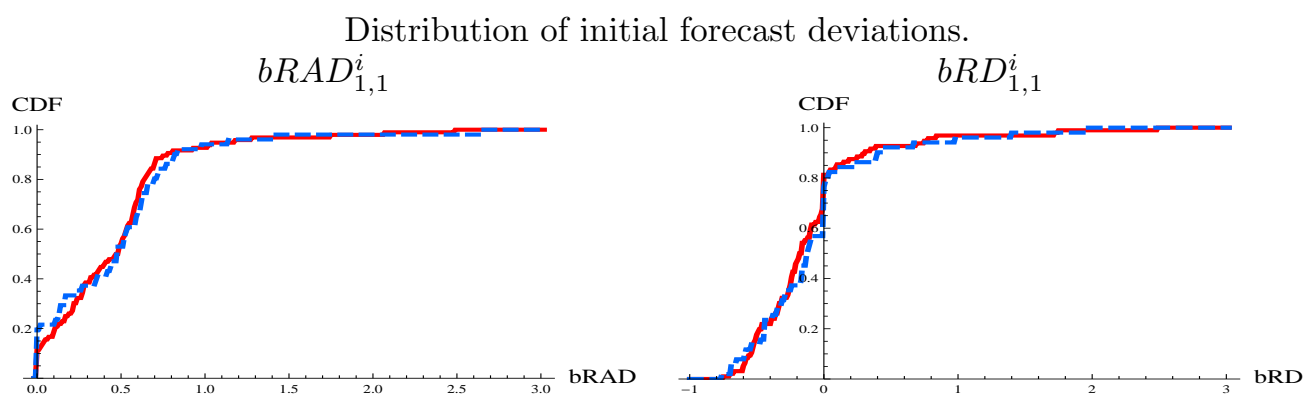

Figure 2: The cumulative distribution for $b R A D_{1,1}^{i}$ (left) and $b R D_{1,1}^{i}$ (right) for $1 \mathrm{H} 5 \mathrm{C}$ and $6 \mathrm{H}$. Dashed lines: 1H5C. Solid lines: $6 \mathrm{H}$. Number of samples is $50(1 \mathrm{H} 5 \mathrm{C})$ and $96(6 \mathrm{H})$.

$$
\mathrm{bRD}_{t, r}^{i}=\frac{1}{N-t+1} \sum_{p=t}^{N} \frac{f_{t, p, r}^{i}-F V_{p}}{|\overline{F V}|},
$$

where $N$ is the number of periods ( $N=10$ in our experiment), $f_{t, p, r}^{i}$ is the forecast price of the period $p$ asset price submitted by subject $i$ in period $t$ of round $r, F V_{p}$ is the fundamental value of the asset in period $p$, and $|\overline{F V}|$ is the absolute value of the average fundamental value of the asset over all periods. ${ }^{27}$ When subject $i$, in round $r$, forecast that no transaction would take place in period $p$, we set $f_{t, p, r}^{i}=F V_{p}$ so there is no deviation in forecast price from the fundamental value. ${ }^{28}$ The only difference between $b R A D$ and $b R D$ is the use of the absolute value. As noted by Stöckl, Huber, and Kirchler (2010), these two measures are complementary in that while $b R A D$ shows the magnitude of the forecast deviations, $b R D$ shows the direction of these deviations.

Figure 2 shows the distribution of the two measures of initial forecast deviations, $b R A D_{1,1}^{i}$ (left)

\footnotetext{
${ }^{27}$ We omit the subscript $r$ for $F V_{p},|\overline{F V}|$, and $N$ because they remain constant across all three rounds in our experiment. One could also consider normalizing the measure using the average fundamental value of the asset over the remaining periods from period $t$. We avoid this to keep the denominator constant for all $t$.

${ }^{28} \mathrm{We}$ also construct bRAD and bRD by dropping the non-transaction forecasts. The results are very similar. See the appendix.
} 


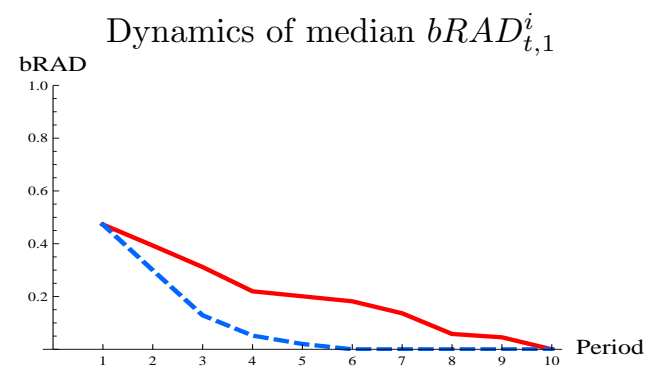

Figure 3: The dynamics of median $b R A D_{t}^{i}, 1$ for $1 \mathrm{H} 5 \mathrm{C}$ and $6 \mathrm{H}$. Dashed lines: $1 \mathrm{H} 5 \mathrm{C}$. Solid lines: $6 \mathrm{H}$. and $b R D_{1,1}^{i}$ (right), for $6 \mathrm{H}$ (solid lines) and 1H5C (dashed lines). We do not reject the null hypothesis that the observed distributions of $b R A D_{1,1}^{i}$ and $b R D_{1,1}^{i}$ for the two treatments are drawn from the same underlying distribution. ${ }^{29}$ Thus, we do not observe that uncertainty about others' rationality has an effect on the initial forecast deviations from the fundamental values.

The magnitudes of forecast deviations from the fundamental values, however, become significantly smaller in $1 \mathrm{H} 5 \mathrm{C}$ than in $6 \mathrm{H}$ after several periods of trading. Figure 3 shows the dynamics of median $b R A D_{t, 1}^{i}$ (that is, from round 1) for $1 \mathrm{H} 5 \mathrm{C}$ (dashed lines) and $6 \mathrm{H}$ (solid lines). While the median $b R A D_{t, 1}^{i}$ is the same in period 1 , it becomes significantly different by period $4 .^{30}$

This difference in the dynamics of forecast deviations can be easily understood from the difference in the observed prices in two treatments. While the prices follow the FVs exactly in $1 \mathrm{H} 5 \mathrm{C}$, this is not the case in $6 \mathrm{H}$. As one can see from Figure 4, not only do the prices deviate from the fundamental values, there are also a number of cases where no transaction took place in the $6 \mathrm{H}$ treatment.

As one would expect from the dynamics of median $b R A D_{t, 1}^{i}$ between the two treatments, the distributions of forecasts deviations in period 1 become significantly different in the later rounds. As Figure 5 shows, in rounds 2 and 3 , the distribution of $b R A D_{1, r}^{i}$ (for $r=2,3$ ) for the $6 \mathrm{H}$ treatment lies to the right of that for the $1 \mathrm{H} 5 \mathrm{C}$ treatment. In these two rounds, we reject the null hypothesis that the observed distribution of $b R A D_{1, r}^{i}$ for the two treatments are drawn from the same underlying distribution. ${ }^{31}$

\footnotetext{
${ }^{29}$ The $p$-values are 0.817 for $b R A D_{1,1}^{i}$ and 0.558 for $b R D_{1,1}^{i}$ using the two-sided Kolmogorov-Smirnov (KS) test.

${ }^{30}$ The $p$-value is 0.019 using the two-sided Mann-Whitney (MW) test. It should be noted that because subjects in the same group (or market) in the $6 \mathrm{H}$ treatment observed the same realized prices, they are no longer an independent sample after period 2 of round 1 . Thus, for all the observation after period 2 of round 1 , we take the group (market) level averages and use them as an independent sample in conducting our statistical tests. As can be easily computed from information in Table 1 , there are 16 groups in the $6 \mathrm{H}$ treatment. Figure 3 is based on the individual level data.

${ }^{31}$ For both rounds 2 and 3, the $p$-value is less that 0.001 using the two-sided KS test. As noted above, the tests are based on independent samples.
} 


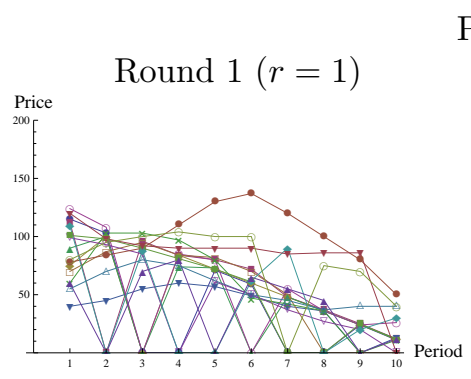

Price dynamics in the $6 \mathrm{H}$ treatment
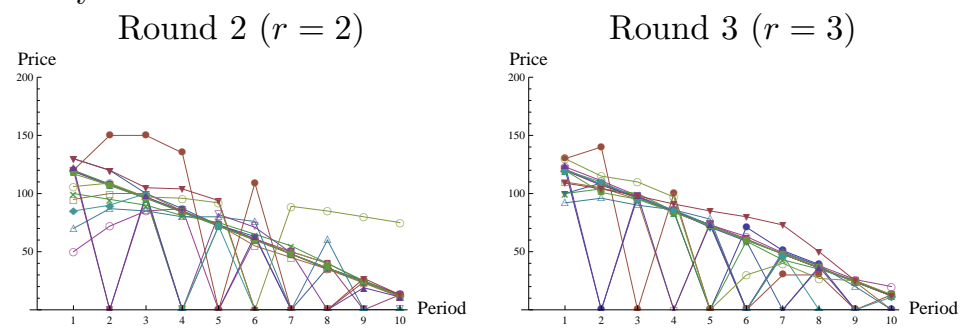

Figure 4: Price dynamics for three rounds of the $6 \mathrm{H}$ treatment for each group. Note that no transaction is represented by a price of 0 .

\section{$3.2 \quad 1 \mathrm{EH} 5 \mathrm{H}$}

Comparing the deviation of the price forecasts from the fundamental values between $6 \mathrm{H}$ and $1 \mathrm{H} 5 \mathrm{C}$ led us to conclude that eliminating the uncertainty about the rationality of others does not result in subjects anticipating the price to more closely follow the fundamental values from the beginning of the experiment. Many subjects in $1 \mathrm{H} 5 \mathrm{C}$, however, learned to expect the price to follow the fundamental values after experiencing the 10-period market once. Did these subjects in $1 \mathrm{H} 5 \mathrm{C}$ who learned to forecast fundamental values understand why the prices follow fundamental values? Namely, did they learn to forecast prices to follow the fundamental values because they are interacting with computer programs that maximize profit without making an error while assuming that all the other traders do the same? Or do they simply expect the same pattern of price dynamics that they have observed, that of prices following the fundamental values, to be repeated again?

To address this issue, we conducted an additional set of experiments in which a subject who has participated in the $1 \mathrm{H} 5 \mathrm{C}$ treatment is recruited again to interact with five inexperienced human subjects (1EH5H). These experienced subjects participated in the $1 \mathrm{H} 5 \mathrm{C}$ treatment in the morning, and recruited back to participate in the $1 \mathrm{EH} 5 \mathrm{H}$ treatment in the afternoon of the same day. The same instructions as in the $1 \mathrm{H} 5 \mathrm{C}$ and $6 \mathrm{H}$ treatments, except for the final part that explains the composition of the traders, are given to all the subjects. Thus experienced subjects have received the same instruction twice. By round 3 in the $1 \mathrm{H} 5 \mathrm{C}$ experiment, the experienced subjects (EH) have all learned that the prices will follow the fundamental values. If they have reasoned that the observed price pattern in $1 \mathrm{H} 5 \mathrm{C}$ was due to the other five traders being computer programs that behaved in a certain way, they may not expect the prices to follow the same pattern after being informed that the other five traders are inexperienced human subjects new to this experiment. Thus, if their initial 
Distribution of initial forecast deviations in round 2

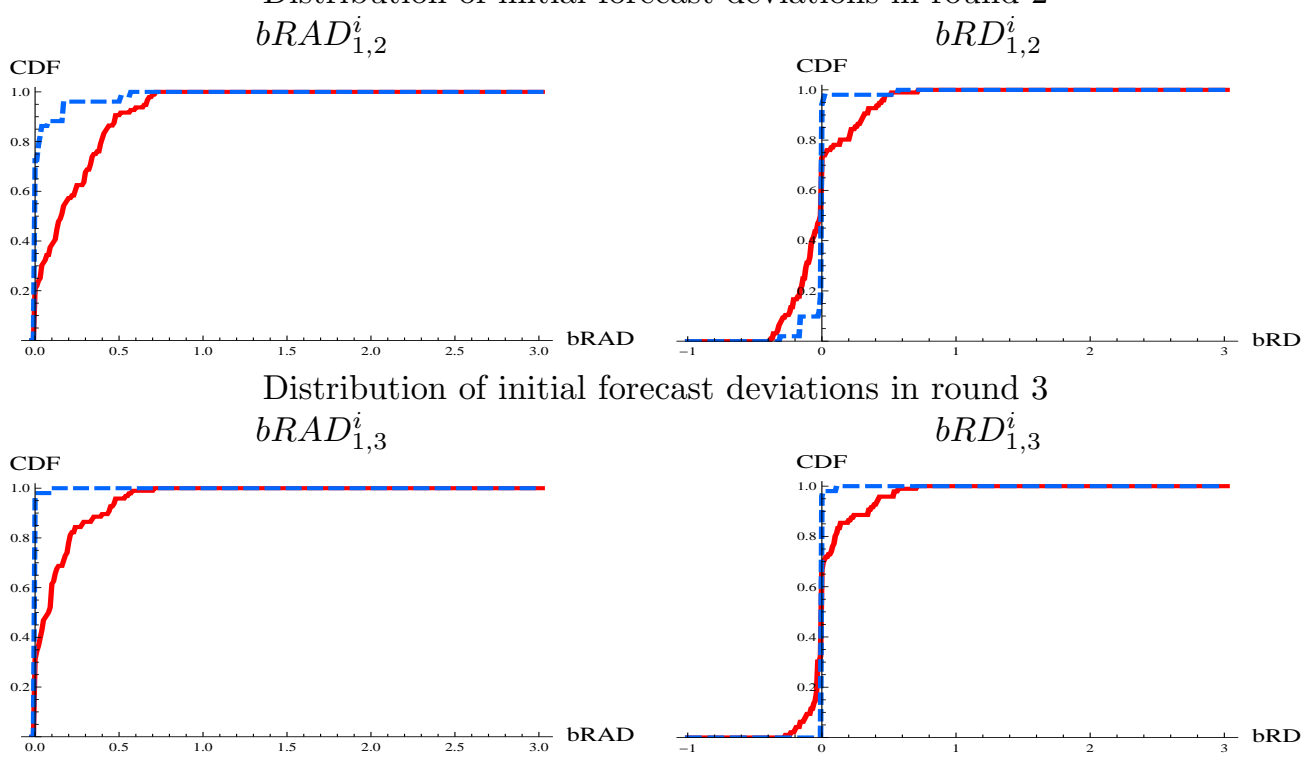

Figure 5: The cumulative distribution of $b R A D_{1, r}^{i}$ (left) and $b R D_{1, r}^{i}$ (right) for $1 \mathrm{H} 5 \mathrm{C}$ and $6 \mathrm{H}$ in round 2 (top) and round 3 (bottom) Dashed lines: 1 H5C. Solid lines: $6 \mathrm{H}$. The number of samples is $50(1 \mathrm{H} 5 \mathrm{C})$ and $96(6 \mathrm{H})$.

price forecasts deviate from the fundamental values in the $1 \mathrm{EH} 5 \mathrm{H}$ treatment, these deviations must be due to their expectations that the inexperienced traders do not behave as computer traders do, i.e., they are uncertain about others' rationality and behavior.

Figure 6 shows the empirical distribution of $b R A D_{1,1}^{i}$ for experienced subjects. It is clear that most of the experienced subjects in this treatment initially forecast prices to follow the fundamental values despite the fact that they were clearly instructed that the other five traders in their market are inexperienced subjects. ${ }^{32}$ This was surprising given how these experienced subjects made their forecasts initially when participating in the $1 \mathrm{H} 5 \mathrm{C}$ treatment just a few hours before. It seems that after participating in the $1 \mathrm{H} 5 \mathrm{C}$ market and observing the prices to follow the fundamental values, it became natural for them to expect the same outcome regardless of who the other traders were in the market. This is clearly at odds with the hypothesis that uncertainty about others' rationality plays a major role in how expectations are formed and how subjects behave in experimental asset markets.

These experienced subjects, however, quickly revised their price forecasts once they had observed

\footnotetext{
${ }^{32}$ Fourteen of the 16 experienced subjects forecast the prices to follow fundamental values. The other two expected only small deviations.
} 


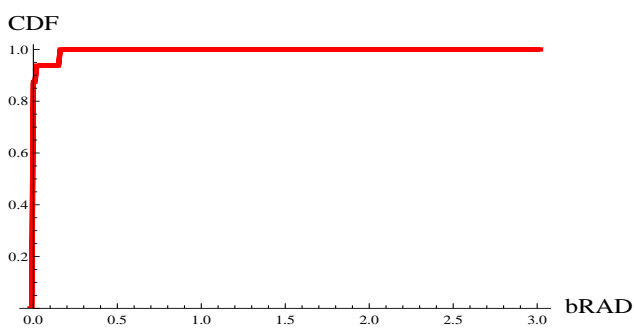

Figure 6: The cumulative distribution of $b R A D_{1,1}^{i}$ for experienced subjects in $1 \mathrm{EH} 5 \mathrm{H}$. There are 16 experienced subjects.
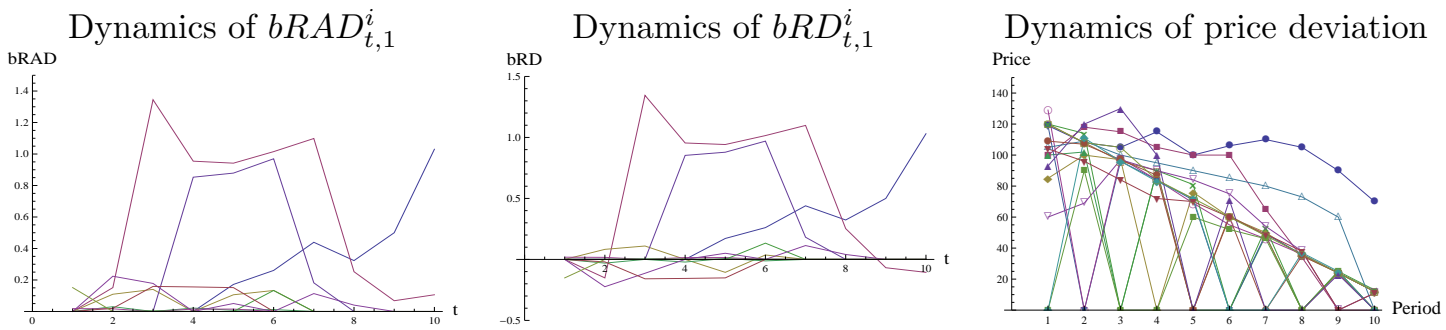

Figure 7: The dynamics of $b R A D_{t, 1}^{i}$ (left) and $b R D_{t, 1}^{i}$ (middle) for experienced subjects (right), and the dynamics of prices (left) in round 1 of the $1 \mathrm{EH} 5 \mathrm{H}$ treatment for each group. Notice that no-transaction is represented by a price of 0 .

the prices to deviate substantially from the fundamental values in this new market with other human traders, as can be seen from Figure 7. This observation suggests that subjects' expectations are driven mainly by the observed prices and not by their expectations of the behavior of others in experimental asset markets.

How about the inexperienced subjects? Does being informed that one of the traders is a subject who has experienced the same experiment and has traded with computer programs changes their expectation significantly compared to the case where all the traders are inexperienced subjects? We have already shown that being informed that the other five traders are computer traders does not result in inexperienced subjects forming significantly different expectations about future prices, so we may expect similar outcomes.

Figure 8 shows the empirical distribution of $b R A D_{1,1}^{i}$ (left) and $b R D_{1,1}^{i}$ (right) for inexperienced subjects from the $1 \mathrm{EH} 5 \mathrm{H}$ treatment (solid lines) and the $6 \mathrm{H}$ treatment (dashed lines). As can easily be seen from the figure, there is no statistically significant difference between the distributions of $b R A D_{1,1}^{i}$ for the $1 \mathrm{EH} 5 \mathrm{H}$ and $6 \mathrm{H}$ treatments. The same is true for the distribution of $b R D_{1,1}^{i} \cdot{ }^{33}$

\footnotetext{
${ }^{33}$ The $p$-values are 0.271 for $b R A D$ and 0,706 for $b R D$ using the two-sided KS test.
} 

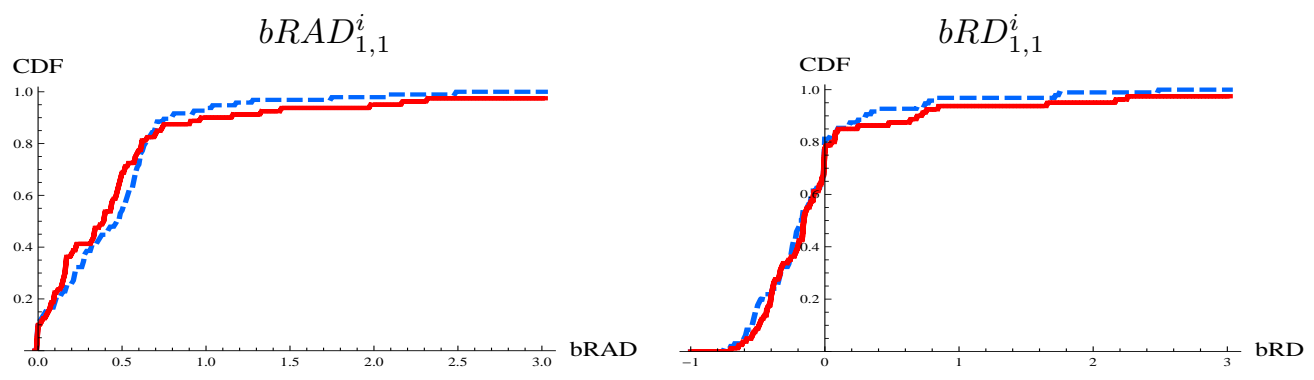

Figure 8: The cumulative distribution of $b R A D_{1,1}^{i}$ (left) and $b R D_{1,1}^{i}$ (right) for inexperienced subjects in the $1 \mathrm{EH} 5 \mathrm{H}$ treatment (solid lines) and $6 \mathrm{H}$ treatment (dashed lines). There are 80 inexperienced subjects in the $1 \mathrm{EH} 5 \mathrm{H}$ treatment and 96 subjects in the $6 \mathrm{H}$ treatment.

\section{Conclusion}

In this paper, we have investigated to what extent the deviation of forecast prices from the fundamental values in experimental asset markets is caused by individual bounded rationality (or confusion) and by uncertainty about the rationality of other traders. We have compared the initial, as well as subsequent, forecast prices submitted by subjects in two market environments - one where all six traders are human subjects $(6 \mathrm{H})$, and the other where one human subject is interacting with five computer traders who submit orders at the fundamental values $(1 \mathrm{H} 5 \mathrm{C})$. Subjects are all told that computer traders maximize their profit without making mistakes while assuming that all other traders do the same. They are also clearly informed about the composition of traders in their group. Our analysis shows that initially there is no significant difference between the deviations of forecasts from the fundamental values in the $6 \mathrm{H}$ and $1 \mathrm{H} 5 \mathrm{C}$ markets. Thus, eliminating uncertainty about other traders' rationality by informing subjects that the other traders are computer traders does not have a significant impact on how initial expectations are formed.

Subjects start forecasting the prices to follow the fundamental values in $1 \mathrm{H} 5 \mathrm{C}$ after observing this outcome for several periods. These changes in expected price can be driven by subjects adjusting their expectation based on the observed price patterns (adaptive expectations) as well as their deeper understanding of the behavior of computer traders. If the latter is the dominant factor, the subjects may not expect the prices to follow the fundamental values when they face human traders who have never participated in similar experiments.

To investigate this issue, we conducted an additional experiment in which one subject who has participated in the $1 \mathrm{H} 5 \mathrm{C}$ treatment (experienced subjects, $\mathrm{EH}$ ) interacts with five other inexperi- 
enced subjects $(1 \mathrm{EH} 5 \mathrm{H})$. The experienced subjects have learned during their participations in the $1 \mathrm{H} 5 \mathrm{C}$ treatment that prices will follow the fundamental values if the other five traders are computer programs. If these subjects reason that the observed price dynamic in $1 \mathrm{H} 5 \mathrm{C}$ is due to the way computer traders behave, and if they expect inexperienced human traders to behave differently, then they should expect the prices to deviate from the fundamental values in this new experiment. Contrary to our expectation, 14 of the 16 experienced subjects initially forecast the price to follow the fundamental values. The other two experienced subjects forecast the prices to deviate only slightly from the fundamental values. Thus, being informed that all the other traders are inexperienced subjects did not play a significant role in these experienced subjects forming their initial price forecasts.

Based on our results, we conclude that uncertainty about the rationality of other traders has no significant impact in explaining the initial deviation of price forecasts from the fundamental values. We, therefore, reinforce the conclusion put forward by Lei, Noussair, and Plott (2001), Huber and Kirchler (2012), and Kirchler, Huber, and Stöckl (2012) that individual bounded rationality (or confusion) is the main driving force of bubbles in these experiments. This is in sharp contrast with the significant effect of uncertainty about others' rationality found in game theoretic experiments such as in Fehr and Tyran (2001), where the nature of strategic interactions are much more salient. Investigation of potential causes of this sharp difference in results may be a fruitful topic for future research to better understand the results reported here.

After observing that the prices deviate from the fundamental values, however, the experienced subjects in the $1 \mathrm{EH} 5 \mathrm{H}$ treatment adjust their price forecasts to deviate from the fundamental values. This result, as well as the way expectations evolved in the $1 \mathrm{H} 5 \mathrm{C}$ and $6 \mathrm{H}$ treatments, are in line with the finding that expectations are adaptive and are driven by previously observed patterns, as presented by Haruvy, Lahav, and Noussair (2007) for the same type of experiment, and Anufriev and Hommes (2012) and Bao, Hommes, Sonnemans, and Tuinstra (2012) for other types of experiment.

Our findings may explain the experimental result reported by Dufwenberg, Lindqvist, and Moore (2005). Dufwenberg, Lindqvist, and Moore (2005) found no significant difference in the price dynamics between markets consisting only of twice-experienced subjects, and those consisting of both (three times) experienced and inexperienced subjects. ${ }^{34}$ Given that realized prices demonstrate sub-

\footnotetext{
${ }^{34}$ Dufwenberg, Lindqvist, and Moore (2005) uses a continuous double auction between six traders with uncertainty about dividend payments.
} 
stantial deviations from the fundamental values even in markets consisting only of twice-experienced subjects, it is quite possible that these experienced subjects continue to expect the price to follow a similar pattern even when they were informed of the change in the composition of traders in the market. ${ }^{35}$ The results may have been somewhat different if the prices followed the fundamental values (as in our 1H5C treatment) for the markets consisting only of twice-experienced subjects. Our result suggests that, if that were the case, then the experienced subjects would expect the prices to follow the fundamental values, while inexperienced subjects would not. Thus, one would expect the magnitude of price deviations from the fundamental values to be smaller in a market with more experienced subjects. Of course, this conjecture needs to be tested experimentally but we leave this to future research.

\footnotetext{
${ }^{35}$ Of course, to see the real impact of the existence of inexperienced subjects, one needs to compare the outcomes between markets that consist only of three times experienced subjects and the mixed market.
} 


\begin{tabular}{ccc} 
Treatment & Number of Subjects & Date \\
\hline $1 \mathrm{H} 5 \mathrm{C}+$ & 11 & May 30, 2012(PM) \\
$6 \mathrm{H}+$ & 24 & May 30, 2012(PM) \\
\hline \hline
\end{tabular}

Table 2: Summary of experimental sessions with instruction including a figure showing declining fundamental values plus a control quiz at the end of instruction.

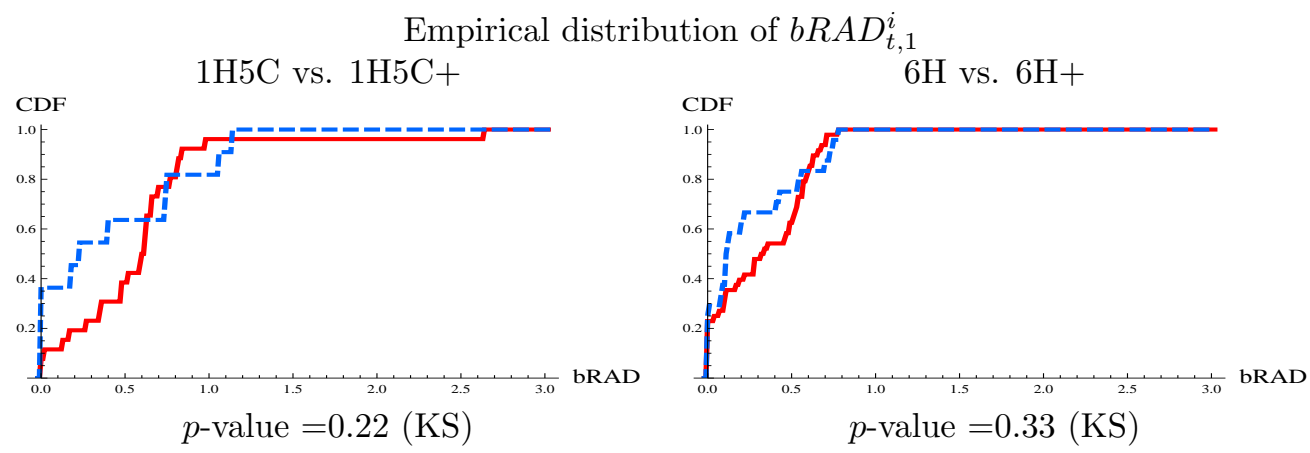

Figure 9: The distribution of $b R A D_{t, 1}^{i}$. Left: $1 \mathrm{H} 5 \mathrm{C}$ (solid lines) vs. $1 \mathrm{H} 5 \mathrm{C}+$ (dashed lines). Right: $6 \mathrm{H}$ (solid lines) vs. $6 \mathrm{H}+$ (dashed lines). We use data from the June 3rd and July 7 th experiments for $1 \mathrm{H} 5 \mathrm{C}$ and $6 \mathrm{H}$ so that the same experimenter read the instructions for $1 \mathrm{H} 5 \mathrm{C}+$ and $1 \mathrm{H} 5 \mathrm{C}$ as well as for $6 \mathrm{H}$ and $6 \mathrm{H}+$.

\section{A Showing a declining figure for FV.}

We ran two experimental sessions where we added a figure showing the fundamental values in our instruction, and also conducted a control quiz ${ }^{36}$ to check understanding of the experiment. Huber and Kirchler (2012) has shown that just showing a figure of fundamental values to subjects dramatically reduces the magnitude of price deviations from the fundamental values. Our aim was to check whether this is also the case for the magnitude of initial deviations of forecast prices from the fundamental values. These extra experimental sessions are summarized in Table 2 .

Figure 9 compares $b R A D_{1,1}^{i}$ between the sessions with the figure and the control quiz and the sessions without either the figure or the control quiz. We call those with the figure and quiz $1 \mathrm{H} 5 \mathrm{C}+$ and $6 \mathrm{H}+$. Thus, our comparisons are between $b R A D_{1,1}^{i}$ for $1 \mathrm{H} 5 \mathrm{C}+$ (dashed lines) and $1 \mathrm{H} 5 \mathrm{C}$ (solid lines), shown in the left panel, and for $6 \mathrm{H}+$ (dashed lines) and $6 \mathrm{H}$ (solid lines), shown in the right panel. We find no significant difference between two distributions of $b R A D_{1,1}^{i}$ across treatments ( $p$-values from the Kolmogorov-Smirnov (KS) test are reported in Figure 9). Therefore, we expect the main results reported in the text to be very similar even if the figure and quiz were included to

\footnotetext{
${ }^{36}$ We based the quiz on that used by Deck, Porter, and Smith (2011) and modified it to fit our purpose. We thank Cary Deck for sharing their quiz with us.
} 
further reduce possible confusion.

\section{B Alternative measures of forecasts deviations}

We next present results based on alternative measures of forecast deviations from the fundamental values. In the main text, we set $f_{t, p, r}^{i}-F V_{p}=0$ whenever $f_{t, p, r}^{i}=0$ because subjects who forget that "computer traders prefer to trade when indifferent between trading and not-trading" may expect no transaction to take place at the fundamental value. Further, in the $6 \mathrm{H}$ treatment, there were a number of periods where no transaction took place. A possible effect this may have is that the magnitude of forecast deviations becomes small for subjects predicting no transactions. To ensure that the way we treated no-transaction forecasts is not driving our result, we use an alternative definition of forecast deviation by dropping no-transaction forecasts in computing the forecast deviations:

$$
\operatorname{bRAD}_{t, r}^{i}=\frac{1}{N-t+1-n t_{t, r}^{i}} \sum_{p=t}^{N} \frac{\Gamma_{t, p, r}^{i}\left|f_{t, p, r}^{i}-F V_{p}\right|}{|\overline{F V}|}
$$

where $\Gamma_{t, p, r}^{i}$ is an indicator function that takes the value one when subject $i$ has forecast a transaction to take place, that is, $f_{t, p, r}^{i} \neq 0$, when submitting his/her forecasts at the beginning of period $t$ in round $r$, and is zero otherwise, while $n t_{t, r}^{i}$ is the number of periods such that $\Gamma_{t, p, r}^{i}=0$. This measure is not defined for subject $i$ in period $t$ if $\mathrm{s} /$ he has forecast that no transaction will take place in all the remaining periods. This happened mostly in periods 9 and 10 of each round.

As can be seen from comparing Figure 5 in the main text with Figure 10 above, the results are basically the same, with the distributions of $b R A D 2$ slightly shifted toward the right of those for $b R A D$. 

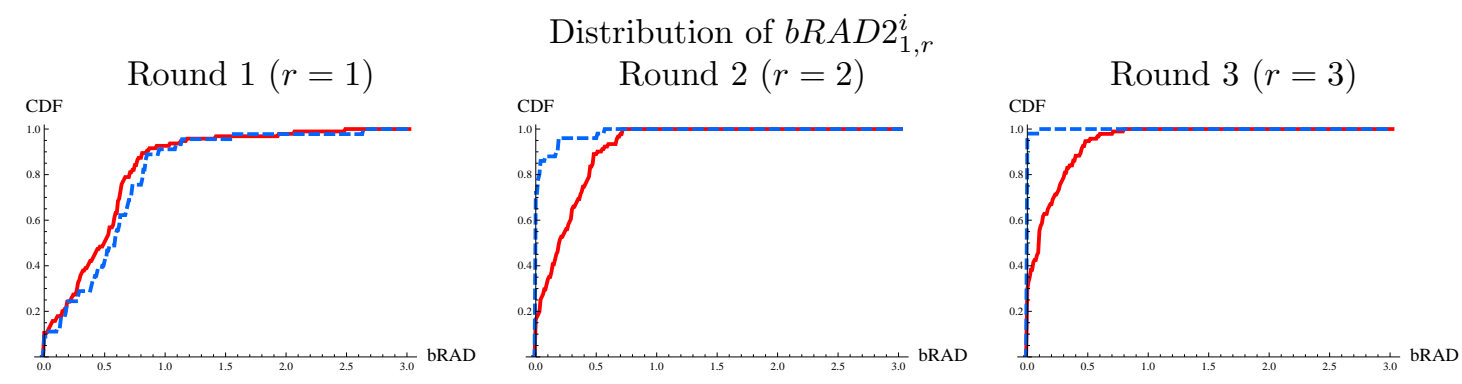

Figure 10: The distribution of $b R A D 2_{1, r}^{i}$ in period 1 across three rounds for $1 \mathrm{H} 5 \mathrm{C}$ and $6 \mathrm{H}$. Dashed lines: $1 \mathrm{H} 5 \mathrm{C}$. Solid lines: $6 \mathrm{H}$.

\section{Instruction}

English translations of the instructions, the script and the slides shown, can be downloaded from:

- http://www.vcharite.univ-mrs.fr/ nobi/assetM/slides.pdf (slides)

- http://www.vcharite.univ-mrs.fr/ nobi/assetM/instructionText.pdf (script read)

- http://www.vcharite.univ-mrs.fr/ ${ }^{\sim}$ nobi/assetM/QuizAndAnswer.pdf (quiz used in 1H5C+ and $6 \mathrm{H}+)$

The set of instructions in Japanese is available upon request.

\section{References}

Anufriev, M., And C. Hommes (2012): "Evolutionary selection of individual experctations and aggregate outcomes in asset pricing experiments," American Economics Journal, Microeconomics, forthcoming.

Bao, T., C. Hommes, J. Sonnemans, and J. Tuinstra (2012): "Individual expectations, limited rationality and aggregate outcomes," Journal of Economic Dynamics and Control, 36, 1101-1120.

CAmerer, C. F. (2003): Behavioral Game Theory: Experiments in Strategic Interaction. Russell Sage Foundation, New York.

Cason, T. N., and D. Friedman (1997): "Price Formation in Single Call Markets," Econometrica, $65(2), 311-345$ 
Costa-Gomes, M. A., and V. P. Crawford (2006): "Cognition and Behavior in Two-Person Guessing Games: An Experimental Study," American Economic Review, 96(5), 1737-1768.

Crawford, V. P., M. A. Costa-Gomes, and N. Iriberri (2012): "Structural Models of Nonequilibrium Strategic Thinking: Theory, Evidence, and Applications," Journal of Economic Literature, forthcoming.

Deck, C., D. Porter, And V. Smith (2011): "Double Bubbles in Assets Markets with Multiple Generations," University of Arkansas and Chapman University.

Dufwenberg, M., T. Lindqvist, and E. Moore (2005): "Bubbles and Experience: An Experiment," American Economic Review, 95, 1731-1737.

Fehr, E., And J.-R. Tyran (2001): "Does Money Illusion Matter?," American Economic Review, $91(5), 1239-1262$.

— (2005): "Individual Irrationality and Aggregate Outcomes," Journal of Economic Perspectives, 19, 43-66.

(2008): "Limited Rationality and Strategic Interaction: The Impact of the strategic environment on nominal inertia," Econometrica, 76(2), 353-394.

FischBACHER, U. (2007): "z-Tree: Zurich toolbox for ready-made economic experiments," Experimental Economics, 10(2), 171-178.

Haltiwanger, J., and M. Waldman (1985): "Rational Expectations and the Limits of Rationality: An Analysis of Heterogeneity," American Economics Review, 75(3), 326-340.

_ (1989): "Limited Rationality and Strategic Complements: The implications for macroeconomics," Quarterly Journal of Economics, 104, 463-484.

Haruvy, E., Y. Lahav, And C. N. Noussair (2007): "Traders' Expectations in Asset Markets: Experimental Evidence," American Economics Review, 97(5), 1901-1920.

Haruvy, E., And C. N. Noussair (2006): "The Effect of Short Selling on Bubbles and Crashes in Experimental Spot Asset Markets," Journal of Finance, 61, 1119-1157. 
Heemeijer, P., C. Hommes, J. Sonnemans, and J. Tuinstra (2009): "Price stability and volatility in markets with positive and negative expectations feedback: An experimental investigation," Journal of Economic Dynamics and Control, 33, 1052-1072.

Ho, T.-H., C. Camerer, and K. Weigelt (1998): "Iterated Dominance and Iterated Best Response in Experimental "p-Beauty Contests"," American Economic Review, 88(4), 947-969.

Huber, J., And M. Kirchler (2012): "The impact of instructions and procedure on reducing confusion and bubbles in experimental asset markets," Experimental Economics, 15, 89-105.

Hussam, R. N., D. Porter, and V. L. Smith (2008): "Thar She Blows: Can Bubbles Be Rekindled with Experienced Subjects?," American Economic Review, 98, 927-934.

King, R. R., V. L. Smith, A. W. Williams, and M. van Boening (1993): "The Robustness of Bubbles and Crashes in Experimental Stock Markets," in Nonlinear Dynamics and Evolutionary Economics, ed. by R. H. Day, and P. Chen, chap. 13, pp. 183-200. Oxford University Press.

Kirchler, M., J. Huber, And T. Stöckl (2012): "Thar She Bursts: Reducing Confusion Reduces Bubbles," American Economic Review, 102(2), 865-883.

Lei, V., C. N. Noussair, and C. R. Plott (2001): "Nonspeculative Bubbles in Experimental Asset Markets: Lack of Common Knowledge of Rationality vs. Actual Irrationality," Econometrica, $69,831-859$.

NAGEL, R. (1995): “Unraveling in Guessing Games: An Experimental Study," American Economics Review, 85(5), 1313-1326.

Noussair, C., S. Robin, And B. Ruffieux (2001): "Price Bubbles in Laboratory Asset Markets with Constant Fundamental Values," Experimental Economics, 4, 87-105.

Noussair, C. N., G. Richter, and J.-R. Tyran (2012): "Money Illusion and Nominal Inertia in Experimental Asset Markets," Journal of Behavioral Finance, 13(1), 27-37, Working Paper 2008-29.

Porter, D. P., And V. L. Smith (1995): "Futures Contractinga and Dividend Uncertainty in Experimental Asset Markets," The Journal of Business, 68(4), 509-541. 
Smith, V. L., G. L. Suchanek, and A. W. Williams (1988): "Bubbles, Crashes. and Endogenous Expectations in Experimental Spot Asset Markets," Econometrica, 56, 1119-1151.

Stöckl, T., J. Huber, And M. Kirchler (2010): "Bubble measures in Experimental Asset Markets," Experimental Economics, 13, 284-298.

Sutan, A., And M. Willinger (2009): "Guessing with negative feedback: An experiment," Journal of Economic Dynamics and Control, 33, 1123-1133.

van Boening, M. V., A. W. Williams, and S. LaMaster (1993): "Price bubbles and crashes in experimental call markets," Economics Letters, 41, 179-185. 